\title{
Intercellular Trafficking of Gold Nanostars in Uveal Melanoma Cells for Plasmonic Photothermal Therapy
}

\author{
Rubén Ahijado-Guzmán ${ }^{1, *}$, Natalia Sánchez-Arribas ${ }^{1}{ }^{\circledR}$, María Martínez-Negro ${ }^{1}{ }^{1}$,

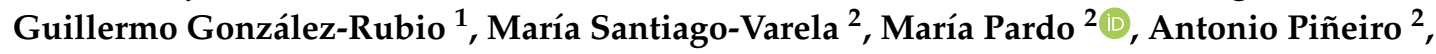 \\ Iván López-Montero ${ }^{1,3} \mathbb{D}$, Elena Junquera ${ }^{1}$ and Andrés Guerrero-Martínez $1, * \mathbb{C}$ \\ 1 Departamento de Química Física, Universidad Complutense de Madrid, Avenida Complutense s/n, \\ 28040 Madrid, Spain; natsanch@ucm.es (N.S.-A.); mmnegro@ucm.es (M.M.-N.); ggrubio@ucm.es (G.G.-R.); \\ ivanlopez@quim.ucm.es (I.L.-M.); junquera@quim.ucm.es (E.J.) \\ 2 Instituto de Investigación Sanitaria de Santiago (IDIS), Xerencia de Xestión Integrada de \\ Santiago (XXIS/SERGAS), Hospital Clínico Universitario de Santiago, Travesía da Choupana s/n, \\ 15706 Santiago de Compostela, Spain; mariasantiagovarela@hotmail.com (M.S.-V.); \\ maruxapardo@hotmail.com (M.P.); anpices@gmail.com (A.P.) \\ 3 Instituto de Investigación Sanitaria Hospital 12 de Octubre (imas12), Avda. Córdoba s/n, \\ 28041 Madrid, Spain \\ * Correspondence: rahijado@ucm.es (R.A.-G.); aguerrero@quim.ucm.es (A.G.-M.); Tel.: +34-934-4274 \\ (A.G.-M.)
}

Received: 12 February 2020; Accepted: 11 March 2020; Published: 24 March 2020

\begin{abstract}
Efficient plasmonic photothermal therapies (PPTTs) using non-harmful pulse laser irradiation at the near-infrared (NIR) are a highly sought goal in nanomedicine. These therapies rely on the use of plasmonic nanostructures to kill cancer cells while minimizing the applied laser power density. Cancer cells have an unsettled capacity to uptake, retain, release, and re-uptake gold nanoparticles, thus offering enormous versatility for research. In this work, we have studied such cell capabilities for nanoparticle trafficking and its impact on the effect of photothermal treatments. As our model system, we chose uveal (eye) melanoma cells, since laser-assisted eye surgery is routinely used to treat glaucoma and cataracts, or vision correction in refractive surgery. As nanostructure, we selected gold nanostars (Au NSs) due to their high photothermal efficiency at the near-infrared (NIR) region of the electromagnetic spectrum. We first investigated the photothermal effect on the basis of the dilution of Au NSs induced by cell division. Using this approach, we obtained high PPTT efficiency after several cell division cycles at an initial low Au NS concentration (pM regime). Subsequently, we evaluated the photothermal effect on account of cell division upon mixing $\mathrm{Au}$ NS-loaded and non-loaded cells. Upon such mixing, we observed trafficking of Au NSs between loaded and non-loaded cells, thus achieving effective PPTT after several division cycles under low irradiation conditions (below the maximum permissible exposure threshold of skin). Our study reveals the ability of uveal melanoma cells to release and re-uptake Au NSs that maintain their plasmonic photothermal properties throughout several cell division cycles and re-uptake. This approach may be readily extrapolated to real tissue and even to treat in situ the eye tumor itself. We believe that our method can potentially be used as co-therapy to disperse plasmonic gold nanostructures across affected tissues, thus increasing the effectiveness of classic PPTT.
\end{abstract}

Keywords: gold nanostars; nanoparticle endocytosis; nanoparticle exocytosis; femtosecond pulse laser; plasmonic photothermal therapy 


\section{Introduction}

The production and application of plasmonic gold nanoparticles (Au NPs) for medical purposes have notably expanded in the last decade due to their remarkable optical properties and high biocompatibility [1-3]. In nanomedicine, gold nanostars (Au NSs) have emerged as promising Au NPs owing to their strong absorption-to-scattering ratio compared to that of, for example, spherical Au NPs with similar sizes [4,5]. Moreover, Au NSs are attracting further attention on account of their tunable localized surface plasmon resonance (LSPR) response, which can be readily shifted to the near-infrared (NIR) region of the electromagnetic spectrum [6,7]. These optical features, located within the optical window of biological tissue (650-1000 nm) [8,9], make Au NSs particularly suitable for in vitro and in vivo applications, such as potential materials for plasmonic photothermal therapy (PPTT) [10-12].

PPTT employs cell-internalized Au NPs to turn non-harmful laser light into thermal energy resulting from the interaction of laser radiation and the LSPR of the plasmonic nanostructures [13]. The so-generated intracellular heating has shown high PPTT efficiency for killing cancer cells through apoptosis [14] and/or photothermolysis [11] processes. In respect to the morphology of the nanocrystals, the strong subwavelength confinement of light near the boundary of anisotropic Au NPs has been effectively used to induce cell death $[3,4,15]$, suggesting the potential application of such systems in cancer treatment. In this sense, Au NSs with highly morphological anisotropy have been successfully employed for the enhancement of PPTT [12].

Regarding the laser source, under continuous wave (CW) laser irradiation, the overall effect of mild thermal heating on Au NSs is intense enough to induce the apoptosis of cancer cells [11]. Complementary to CW sources [16], pulse lasers enable irradiation with low fluences in ultrashort periods of time, allowing PPTT effects through the highly localized heating of intracellular Au NPs [15]. Interestingly, the maximum permissible exposure (MPE) threshold of skin using pulse lasers $\left(0.4 \mathrm{~W} / \mathrm{cm}^{2}\right.$ at $850 \mathrm{~nm}$ ) [17] is often exceeded using spherical Au NPs [16]. However, there are examples of effective PPTT in cancer cells using Au NSs [12] or Au nanorod assemblies [18] under excitation with a NIR femtosecond (fs) laser at a power density of $\sim 0.2 \mathrm{~W} / \mathrm{cm}^{2}$, which is below the required MPE threshold of skin.

The cellular response to Au NPs can be potentially exploited as a tool for alternative cancer therapies. In general, cells, due to their unsettled capacity to uptake, retain, release, and re-uptake Au NPs, offer enormous opportunities for research by varying the cell line characteristics and the Au NP size, shape, and surface modification [19-21]. While a few studies exist on the ability for re-endocytosis of $\mathrm{Au}$ NPs and their dilution due to cell division [22,23], the consequences of intercellular trafficking during PPTT remain unclear [22]. Additionally, uveal malignant melanoma is the most common primary intraocular tumor in adults. Currently, the most commonly used local treatments for this tumor are brachytherapy (iodine-125, ruthenium-106, or palladium-103, or cobalt-60) and teletherapy (proton beam, helium ion, or stereotactic radiosurgery using a cyber knife, gamma knife, or linear accelerator); the alternative to radiation is eye enucleation [24,25]. In this context, uveal melanoma cells offer an excellent biological environment to study due to the ubiquitous use of NIR CW and pulse lasers in multiple types of eye surgery [26-28].

Inspired by these precedents, we have tackled the in vitro study of PPTT in uveal melanoma cells loaded with $\mathrm{Au}$ NSs under irradiation with a fs pulse laser (800 nm Ti:sapphire 90 fs laser pulses, $80 \mathrm{MHz}$ ) by two different approaches. On the one hand, we have investigated the photothermal effect associated with the dilution of Au NSs generated during cell division. The use of Au NSs with the LSPR band centered at $800 \mathrm{~nm}$, combined with low pulse laser irradiation at the NIR $\left(0.21 \mathrm{~W} / \mathrm{cm}^{2}\right.$, below the MPE threshold of skin), afforded high PPTT efficiency after three and four cell-division cycles at Au NS concentrations of $2 \mathrm{pM}$ and $8 \mathrm{pM}$, respectively. On the other hand, we have examined the PPTT response upon cell division and in the presence of exocytosis/re-endocytosis processes by mixing Au NS-loaded and non-loaded cells. At an effective Au NS concentration of 4 pM, we observed trafficking of Au NSs between loaded and non-loaded cells, resulting in effective PPTT under optimal low irradiance conditions, even after four division cycles. Therefore, our study reveals the ability of 
these cells to release and re-uptake Au NSs that retain their unique photothermal properties throughout several cell division cycles. These findings can potentially be used as an alternative co-therapy to disperse plasmonically active gold nanostructures across affected tissues in situ or the eye itself, thus increasing the effectiveness of classic PPTT.

\section{Results and Discussion}

Plasmonic Au NSs with sizes of $50.2 \pm 4.0 \mathrm{~nm}$ analyzed by transmission electron microscopy TEM (Figure 1a), and LSPR band centered at ca. $800 \mathrm{~nm}$ (Figure 1b), were synthesized by a colloidal seed-mediated growth method (see Materials and Methods Section) [29]. The synthesis was based on the preparation of citrate seeds of $14.0 \pm 1.0 \mathrm{~nm}$, and a subsequent growing and branching step in which Au NSs (56 $\pm 6 \mathrm{~nm}$ measured by dynamic light scattering; zeta potential of $-21 \pm 1 \mathrm{mV}$ in good agreement with previous results [30]) functionalized with a thiol-modified polyethylene glycol (PEG-SH, $6 \mathrm{kDa}$ ) were obtained [31], in order to prevent aggregation at physiological ionic strengths (Figure 1b) and provide excellent biocompatibility [32]. To test the cytotoxicity of the Au NSs, uveal melanoma cells were incubated at an Au NS dose of 8 pM for $12 \mathrm{~h}$. An uptake of approximately $90 \%$ of $\mathrm{Au}$ NSs was estimated by TEM and from the removed culture media (see Materials and Methods). Figure 1c shows the relatively high viability of the incubated cells during a period of 19 days, where no depletion of the cell activity was observed.
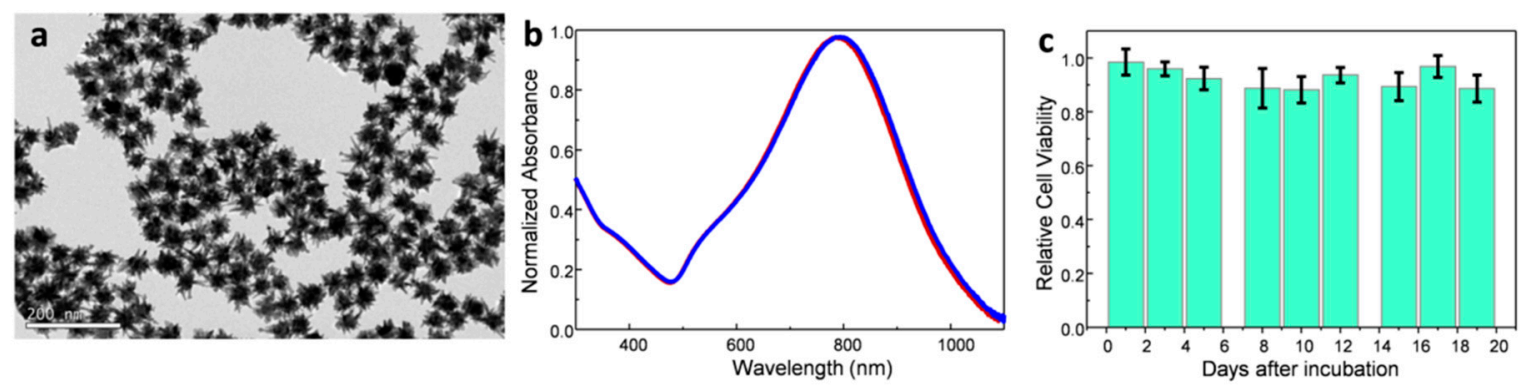

Figure 1. (a) TEM image of the synthetized Au NSs. (b) UV-vis-near-infrared (NIR) spectra of the gold nanostars (Au NS) colloidal solution with the localized surface plasmon resonance (LSPR) band at ca. $800 \mathrm{~nm}$ (red) and at $795 \mathrm{~nm}$ (blue), before and after transfer to physiological conditions, respectively. (c) Cell viability test after $12 \mathrm{~h}$ of incubation of Au NSs with uvea cells ( 3 independent samples were tested and averaged; the error bars show the standard deviation of the relative cell viability). The cell viability shows cell survival above $90 \%$ after 19 days.

To understand the intercellular trafficking properties of Au NSs and their impact on PPTTs, two different sets of experiments were designed (Figure 2). The first strategy consisted of the incubation of uveal melanoma cells with Au NSs at different concentrations for $12 \mathrm{~h}$ (Figure 2a). After incubation and washing, and once $95 \%$ confluence had been reached, the cell culture was divided in two different stocks with approximately $50 \%$ of the cells. While the first stock was used in PPTT experiments, the second one was left in culture until 95\% confluence. Then, the second stock was divided again in two equal stocks to repeat the previous step. This strategy was repeated five times until six consecutive cell cultures were obtained. In a second strategy, fresh cells and Au NS-loaded cells were incubated together at a 1:1 ratio (Figure $2 b$ ). Once the culture reached 95\% confluence, the first strategy was followed again until six consecutive cell cultures were obtained.

Regarding the first strategy, the TEM analysis confirmed that cells were able to uptake, release, and re-uptake Au NSs, where, on average, the number of Au NSs was divided in half during cell division. As representative TEM micrographs, Figure 3a,b show a single cell loaded with a large amount of Au NSs (see also Figures S1 and S2) after 12 h of incubation at an Au NSs dose of 8 pM. On the contrary, after $48 \mathrm{~h}$ of incubation, the TEM images show many intercellular regions of exocytosis with non-agglomerated Au NSs (Figure 3c,d). Interestingly, small vesicular compartments of Au NSs 
inside the cells were observed around the exocytosis regions (see Figure S3). These observations are consistent with previous studies that revealed the dilution and re-endocytosis of Au NPs during cell division [23].

a

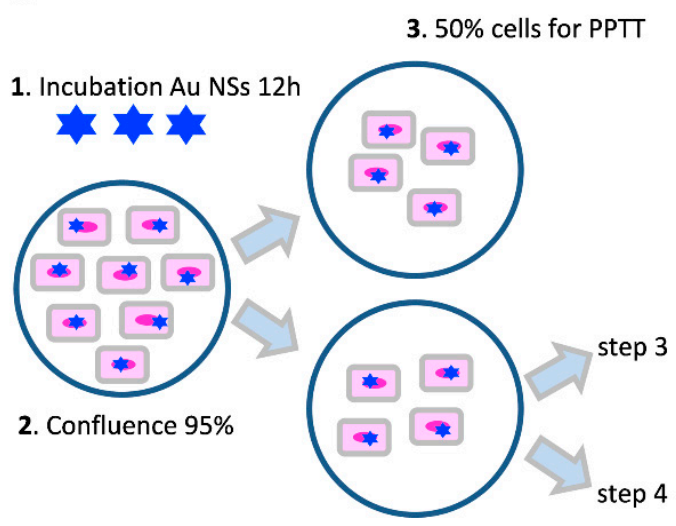

4. $50 \%$ cells until $95 \%$ confluence b

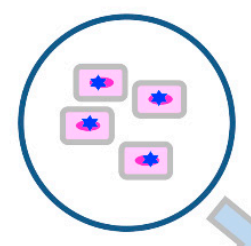

1. $50 \%$ cells + Au NSs $50 \%$ cells - Au NSs

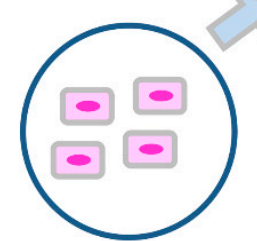

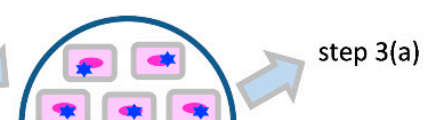

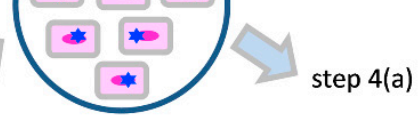

Figure 2. (a) Approach one: 1. Incubation of Au NSs for $12 \mathrm{~h}$ with uveal melanoma cells. 2. When the culture reached $95 \%$ confluence, the cells were divided in two different stocks. 3 . The first stock with $50 \%$ of the cells was used for laser experiments. 4 . The second stock with the other $50 \%$ of the cells was left in culture until $95 \%$ confluence, at which point it was again divided in two equal stocks to repeat the process. (b) Fresh cells and Au NS-loaded cells (8 pM) were mixed at a 1:1 ratio (i.e., Au NS effective concentration of $\sim 4 \mathrm{pM}$ ). When the culture reached $95 \%$ confluence, it was split in two as explained above (steps 3 and 4 ) and the process was repeated five times.

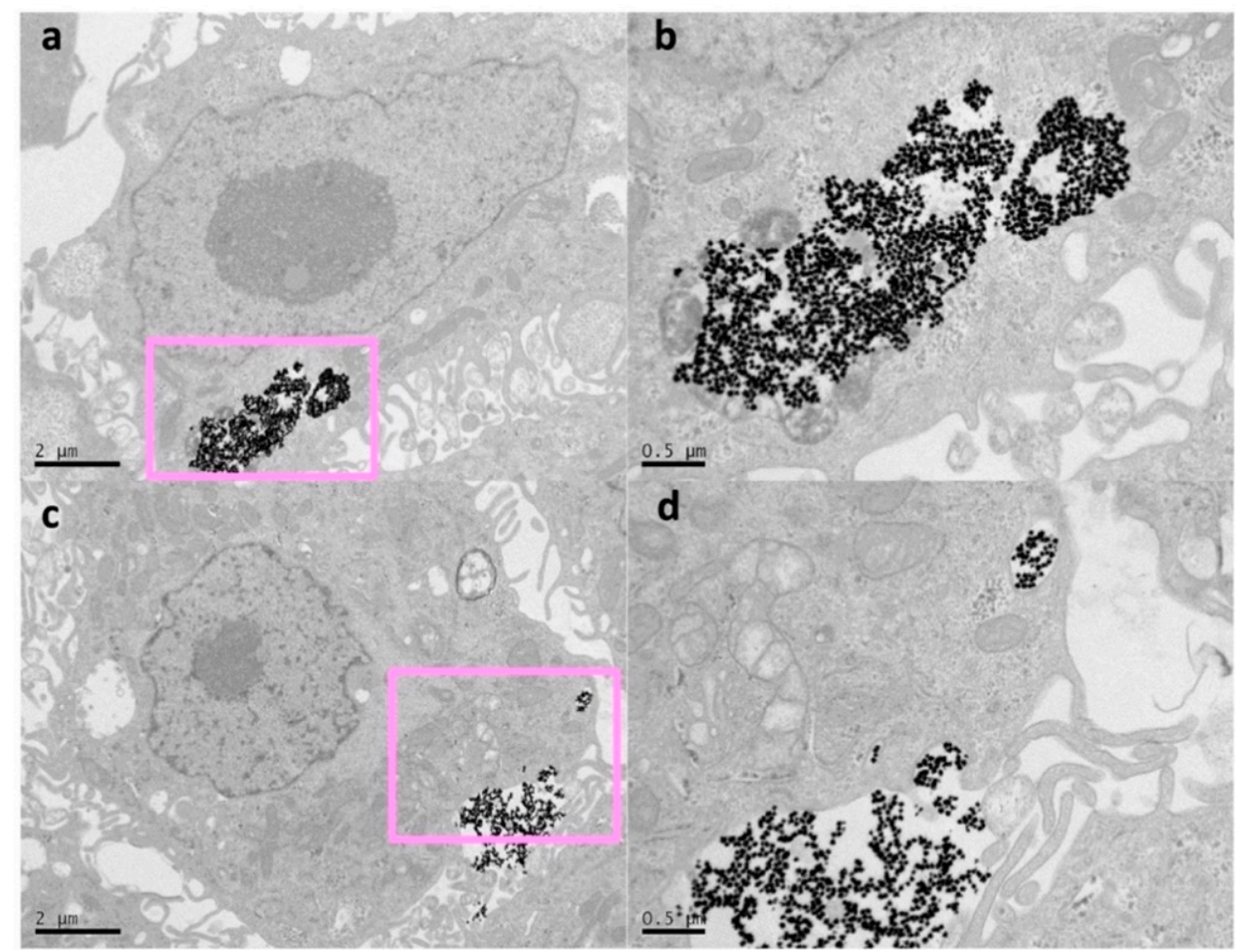

Figure 3. (a) TEM micrograph of a single cell loaded with Au NSs and (b) image at higher magnification after incubation with 8 pM Au NSs. (c) Micrograph after $48 \mathrm{~h}$ of incubation and (d) image at higher magnification, in which many regions can be seen where the Au NSs have been exocyted and locate between two cells, as well as small vesicular compartments with smaller amounts of Au NS. 
In addition, photothermolysis of the cancer cells at different division stages was evaluated by fs laser irradiation at different power densities (from 0 to $1.41 \mathrm{~W} / \mathrm{cm}^{2}$ ), maintaining a relatively high exposure surface $\left(20 \mathrm{~mm}^{2}\right)$ and low irradiation time $(1 \mathrm{~min})$. Right after incubation with the Au NSs (Figure 4a), an important killing rate was observed using laser power densities equal to or above $0.21 \mathrm{~W} / \mathrm{cm}^{2}$. These power densities are in good agreement with previous results observed for single gold nanorods stabilized with analogous PEG-SH ligands and lower plasmonic efficiencies at the NIR [18]. Very similar results were observed from the first to the fourth cell passage (Figure $4 \mathrm{~b}-\mathrm{e}$ ), with small differences of $10-20 \%$ in cell survival upon applying a laser power density of $0.21 \mathrm{~W} / \mathrm{cm}^{2}$ (below the MPE threshold of skin). Interestingly, at the fifth passage, power densities of at least $0.42 \mathrm{~W} / \mathrm{cm}^{2}$ were required to reach similar cell killing rates (Figure 4f). Therefore, we conclude that an Au NS dilution effect is, in principle, triggered by cell division, considering that exocytosis and re-uptake are able to maintain the Au NS concentration approximately constant. At this point, the Au NS concentration was estimated to be $180 \pm 100 \mathrm{Au}$ NS/cell by TEM analysis (see Section 4 and Figure S4).

To corroborate such an Au NS dilution effect, we repeated the same set of experiments with cells incubated at a lower Au NS concentration (2 pM). As expected, a reduction of the PPTT effectiveness was observed in the fourth passage, where power densities of at least $0.42 \mathrm{~W} / \mathrm{cm}^{2}$ were required to obtain significant cell killing rates (Figures S5 and S6). Due to the proximity between the PPTT effectiveness between irradiations at 2 and $8 \mathrm{pM}$ (three and four cell passages, respectively), no intermediate concentrations of Au NSs were considered. Additionally, we did not observe significant differences of the intercellular regions of endo/exocytosis with the concentration of Au NSs, only related to the amount of loaded nanoparticles at these locations (Figure 3 and Figure S7).
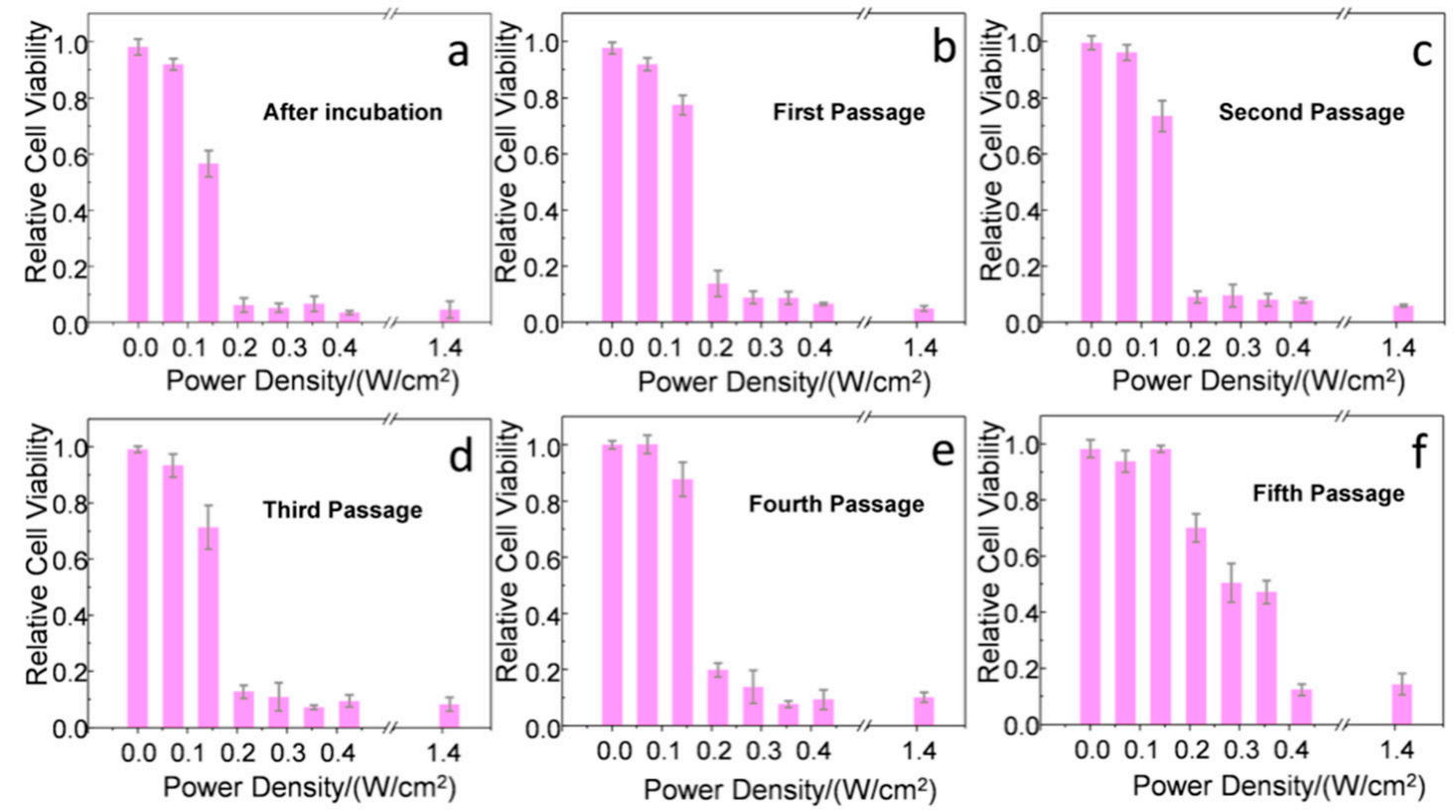

Figure 4. Cell viability as a function of the applied fs laser power density ( 3 independent samples were tested and averaged at each power density; the error bars show the standard deviation of the relative cell viability). (a) After incubation with Au NSs, we observed an important killing rate using laser power densities above $0.21 \mathrm{~W} / \mathrm{cm}^{2}$. Similar results were obtained after the first $(\mathbf{b})$, second $(\mathbf{c})$, third (d), and fourth (e) cell passage, with small differences of 10-20\% of cell survival. After the fifth passage (f), a laser power density of at least $0.42 \mathrm{~W} / \mathrm{cm}^{2}$ was required to obtain significant cell killing rates.

In our second approach (Figure 2b), Au NS-loaded cells incubated at an NP concentration of 8 pM were mixed with fresh cells at a 1:1 ratio, affording an effective concentration of Au NSs of 4 pM. After $8 \mathrm{~h}$ of mixing, and using the same laser exposure conditions described before, only around $50 \%$ of the cells were killed by the PPTT treatment (Figure 5a), showing that not enough time had passed to 
allow for intercellular trafficking. However, after the first passage $(72 \mathrm{~h})$, an enhanced killing rate of around $85 \%$ was observed using a laser power density of $0.21 \mathrm{~W} / \mathrm{cm}^{2}$ (Figure $5 \mathrm{~b}$ ). This result indicates that, after uptake and exocytosis processes, the Au NSs are re-endocyted by the initially non-loaded cells with retention of their photothermal properties. From the second to the fourth cell passage (Figure $5 \mathrm{c}-\mathrm{e}$ ), the results are very similar with small differences ranging $10-20 \%$ of cell survival at a laser power density of $0.21 \mathrm{~W} / \mathrm{cm}^{2}$. After the fifth passage, as observed in the case of the first strategy at low $\mathrm{Au}$ NS concentrations, a reduction of the photothermal efficiency was recorded (Figure 5f). In this case, a laser power density of at least $1.42 \mathrm{~W} / \mathrm{cm}^{2}$ was required to reach significant cell killing rates $(\sim 70 \%)$. Therefore, in this second approach, we were able to combine the dilution effect of cell division with a dilution effect upon mixing loaded and non-loaded cells. We estimated the Au NS concentration by TEM analysis to be $3800 \pm 900 \mathrm{Au}$ NS/cell after $72 \mathrm{~h}$ of mixing (Figure S8) and $90 \pm 50$ $\mathrm{Au} \mathrm{NS/cell} \mathrm{after} \mathrm{the} \mathrm{fifth} \mathrm{passage} \mathrm{(Figure} \mathrm{S9).}$
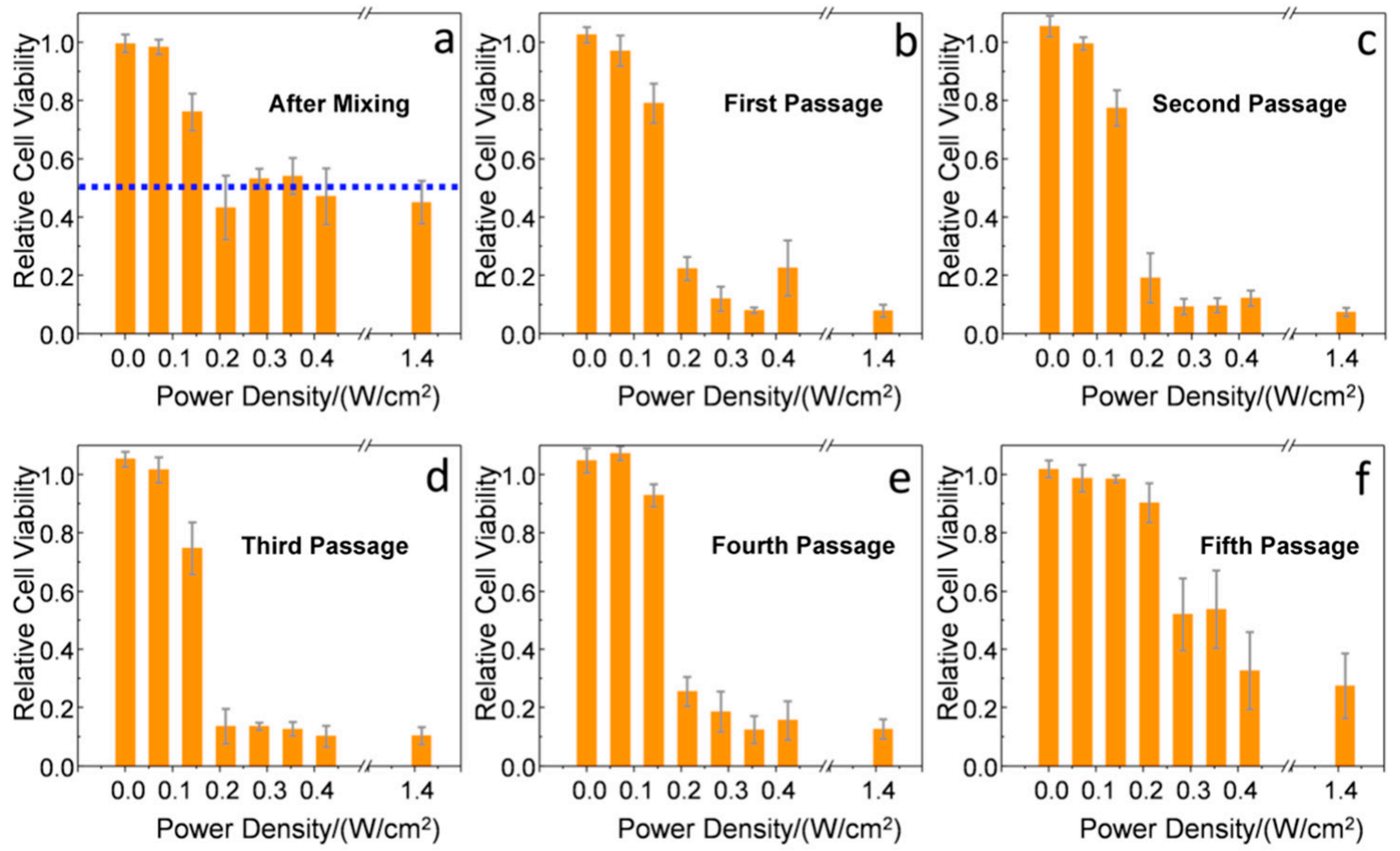

Figure 5. Cell viability as a function of the applied fs laser power density (3 independent samples were tested and averaged at each power density; the error bars show the standard deviation of the relative cell viability). (a) After mixing $50 \%$ of Au NS-loaded cells and $50 \%$ of non-loaded cells, we observed a killing rate of ca. 50\% (see blue dashed line) using laser power densities above $0.21 \mathrm{~W} / \mathrm{cm}^{2}$. After the first (b), second (c), third (d), and fourth (e) cell passage, the cell killing rate increased with small differences (10-20\%) in cell survival using a laser power density of at least $0.21 \mathrm{~W} / \mathrm{cm}^{2}$. After the fifth passage (f), we did not observe important cell killing rates.

We further investigated our second approach by TEM analysis. After $24 \mathrm{~h}$, the TEM images showed membrane invaginations in many cells, indicating exocytosis from the Au NS-loaded cells and re-endocytosis by the non-loaded cells (Figure 6). This observation indicates that the Au NS concentration splits during cell division (as manually performed in our first approach), but also by trafficking from loaded cells to non-loaded cells. 


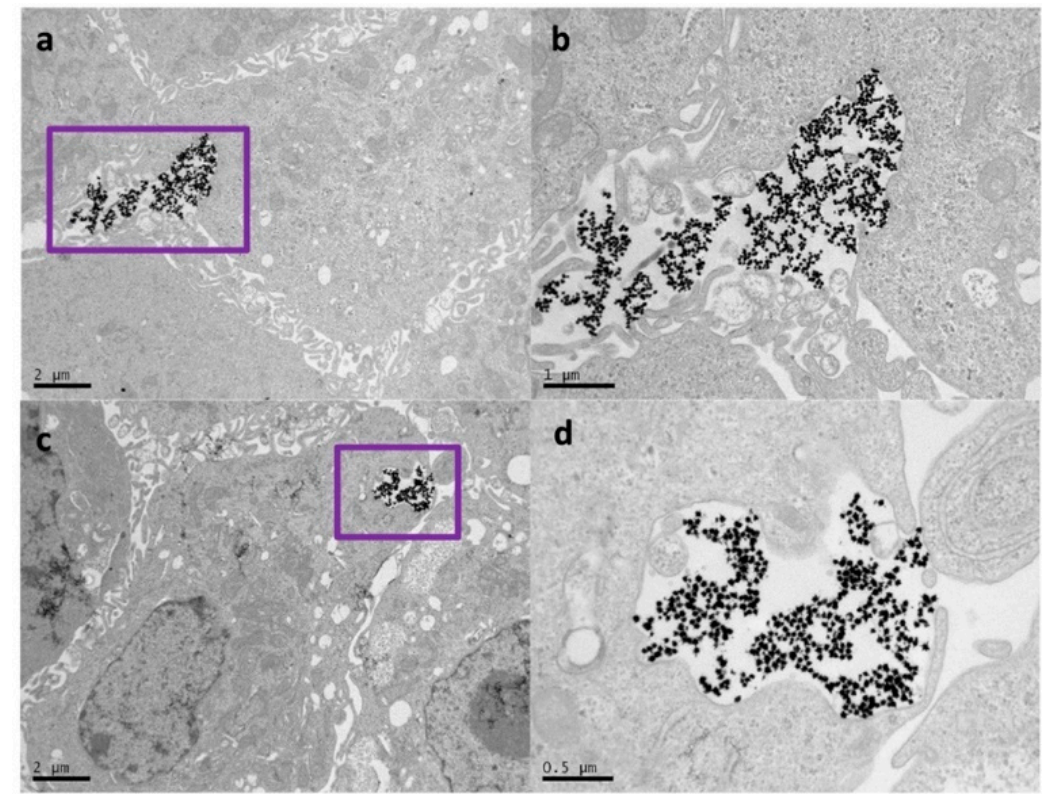

Figure 6. (a) TEM micrograph of a single cell where a big membrane invagination can be observed and (b) image at higher magnification. Another example of the exocytosis and re-endocytosis of Au NSs is shown in (c) and at higher magnification in (d).

\section{Conclusions}

We have studied changes in photothermal effects in regard to the dilution of Au NSs induced by (i) cell division and (ii) by trafficking between Au NS-loaded and non-loaded uveal melanoma cells. In the first approach, we obtained high PPTT efficiency after four cell-division cycles at an initial Au NS concentration of $8 \mathrm{pM}$. In the second approach, we observed trafficking of Au NSs between loaded and non-loaded cells, achieving effective PPTT after four division cycles under the same low irradiance conditions. Our study reveals the ability of uveal melanoma cells to release and re-uptake Au NSs with retention of their plasmonic photothermal properties throughout several cell-division cycles and after cellular re-uptake. These approaches have the potential for use in real tissue and even to treat the eye tumor itself in the near future. We believe that our method may be used as a co-therapy to disperse plasmonic gold nanostructures across affected tissues, thus increasing the effectiveness of classic PPTT.

\section{Materials and Methods}

Materials. All analytical grade reagents, metallic salts, buffers, and cell culture media were purchased from Sigma-Aldrich or Merck (Madrid, Spain). We used Milli-Q deionized water from a Millipore system ( $>18 \mathrm{M} \Omega$, Milli Q) in all the experiments.

Optical Characterization. UV-Vis-NIR characterization was performed on a JASCO-V770 spectrophotometer.

Au NSs Synthesis. Au NSs (50.2 $\pm 4.0 \mathrm{~nm}$ analyzed by TEM; LSPR band centered at ca. $800 \mathrm{~nm})$ were prepared by a modified colloidal seed-mediated growth method [31]. Firstly, to prepare the seed solution, $5 \mathrm{~mL}$ of $1 \%$ citrate solution was added to $100 \mathrm{~mL}$ of boiling $0.45 \mathrm{mM} \mathrm{HAuCl}_{4}$ solution under vigorous stirring. The seeds $(14.0 \pm 1.0 \mathrm{~nm}$ determined by TEM; $14.9 \pm 1 \mathrm{~nm}$ measured by Dynamic Light Scattering (DLS); zeta potential of $-11.8 \pm 0.6 \mathrm{mV}$ ) were citrate-stabilized after $15 \mathrm{~min}$ of boiling (red color). After the seed solution was cooled down to room temperature, $100 \mu \mathrm{L}$ of the seed solution was added under gentle stirring to $20 \mathrm{~mL}$ of $\mathrm{HAuCl}_{4}(0.25 \mathrm{mM})$ solution, containing $20 \mu \mathrm{L}$ of $1.0 \mathrm{M}$ $\mathrm{HCl}$ solution. Following, $200 \mu \mathrm{L}$ of $3 \mathrm{mM} \mathrm{AgNO}_{3}$ and $100 \mu \mathrm{L}$ of $100 \mathrm{mM}$ ascorbic acid solutions were added simultaneously, and $500 \mu \mathrm{L}$ of $0.1 \mathrm{mM}$ PEG-SH (6 kDa) solution was added and mixed during $30 \mathrm{~min}$. Finally, Au NSs ( $56 \pm 6 \mathrm{~nm}$ measured by DLS; zeta potential of $-21 \pm 1 \mathrm{mV}$ ) were washed by centrifugation at $1190 \mathrm{~g}$ and $10{ }^{\circ} \mathrm{C}$ for $25 \mathrm{~min}$, and redispersed in Milli-Q water. 
Zeta Potential and DLS. The phase analysis light scattering technique (Zeta PALS, Brookhaven Instruments Corp., Holtsville, NY, USA) was employed to measure the electrophoretic mobility, which was then used to obtain the zeta potential of the nanoparticles. The nanoparticle size was determined by a DLS method using a particle analyzer (Zeta Nano Series; Malvern Instruments, Barcelona, Spain). In both studies, samples were determined under experimental conditions of $25^{\circ} \mathrm{C}$, a dispersant refractive index of 1.33 (water), a viscosity of $0.9 \mathrm{cP}$, and a dispersant dielectric constant of 78.5. Each zeta potential and particle size data point was taken as the average of 50 and 30 independent measurements, respectively.

Cell Culture and Viability. The primary uveal melanoma cell culture, established from a human uveal melanoma primary tumor [33], was cultured in Dulbecco's modified Eagle's medium (DMEM) supplemented with $10 \%$ FBS, $500 \mathrm{UI} / \mathrm{mL}$ penicillin, and $0.1 \mathrm{mg} / \mathrm{mL}$ streptomycin, and maintained at $37{ }^{\circ} \mathrm{C}$ in $5 \% \mathrm{CO}_{2}$ in a humidified incubator until confluence. The cell viability was evaluated by the Alamar Blue assay (commercial kit from Life Technologies). Following the guidelines of the manufacturer, the cells were incubated in a 96-well plate with 10\% Alamar Blue in DMEM without red phenol for $3 \mathrm{~h}$. The absorbance at $570 \mathrm{~nm}$ was monitored using $600 \mathrm{~nm}$ as the reference wavelength. The viability was determined by comparison with control cells (100\%). All reported experiments were performed in triplicate.

Plasmonic Photothermal Therapy. Photothermal irradiation was performed using a pulsed laser system Ti:sapphire ultrafast oscillator (Tsunami, Spectra-Physics) centered at $800 \mathrm{~nm}$, with a pulse duration of around $90 \mathrm{fs}$ and a repetition rate of $80 \mathrm{MHz}$. The laser power density was controlled by a variable neutral density filter. Au NSs were incubated at concentrations from 2 and $8 \mathrm{pM}$ for $12 \mathrm{~h}$, after which the cells were washed twice with phosphate buffered saline (PBS) buffer and fresh supplemented DMEM was added. The incubated cells contained in a 96-well plate $\left(7 \times 10^{3}\right.$ cells per well) were illuminated for $1 \mathrm{~min}$ with a laser spot diameter of $5 \mathrm{~mm}$. The laser power was evaluated from 0 to $1.41 \mathrm{~W} / \mathrm{cm}^{2}$. After irradiation, the cells were incubated in a 96-well plate with $10 \%$ Alamar Blue in DMEM without red phenol for $3 \mathrm{~h}$ following the manufacturer guidelines. Three independent samples were tested and averaged at each power density.

Transmission Electron Microscopy (TEM). TEM images were obtained on a JEOL JEM-1010 transmission electron microscope operating at an acceleration voltage of $80 \mathrm{kV}$ (CNME, Spain). The cells were incubated with the Au NSs, washed twice with PBS buffer, and fixed with a solution containing $2 \%$ glutaraldehyde in PBS. Then, the cells were stained with a mixture of $1 \%$ osmium tetroxide and $1.5 \%$ potassium cyanoferrate. After two washing cycles, the cells were gradually dehydrated in acetone. The samples were embedded in Epon, sectioned for analysis, and cut by ultramicrotomy for observation. The Au NS uptake levels were estimated from TEM images following a procedure described in the literature [18].

Supplementary Materials: The following are available online at http://www.mdpi.com/2079-4991/10/3/590/s1, Figures S1-S5: TEM micrographs, Figure S6: Cell viability, Figures S7-S9: TEM micrographs.

Author Contributions: R.A.-G. supervised and performed all the experiments, and wrote the manuscript. N.S.-A., M.M.-N., and G.G.-R. contributed to the synthesis and ligand replacement of the Au NSs, optical characterization, TEM measurements and zeta potential and DLS characterization. M.S.-V., M.P., and A.P. established the uveal melanoma cell culture from a primary uveal melanoma tumor. I.L.-M. contributed to the viability experiments. E.J. contributed to the plasmonic photothermal therapy experiments. A.G.-M. conceived the study, designed the experiments, and wrote the manuscript. All authors have read and agreed to the published version of the manuscript.

Funding: This research received no external funding.

Acknowledgments: This work has been funded by the Spanish Ministry of Science, Innovation and Universities (MICIU) (Grant RTI2018-095844-B-I00) and the Madrid Regional Government (Grant P2018/NMT-4389). The facilities provided by the Center for Ultrafast Lasers and the National Center of Electronic Microscopy at Complutense University of Madrid are gratefully acknowledged.

Conflicts of Interest: The authors declare no conflict of interest. 


\section{References}

1. Huang, X.; Jain, P.K.; El-Sayed, I.H.; El-Sayed, M.A. Plasmonic photothermal therapy (PPTT) using gold nanoparticles. Lasers Med. Sci. 2008, 23, 217-228. [CrossRef] [PubMed]

2. Ali, M.R.K.; Wu, Y.; El-Sayed, M.A. Gold-nanoparticle-assisted plasmonic photothermal therapy advances toward clinical application. J. Phys. Chem. C 2019, 123, 15375-15393. [CrossRef]

3. Giljohann, D.; Seferos, D.; Daniel, W.; Massich, M.; Patel, P.; Mirkin, C. Gold nanoparticles for biology and medicine. Angew. Chem. Int. Ed. 2010, 49, 3280-3294. [CrossRef] [PubMed]

4. Chirico, G.; Pallavicini, P.; Collini, M. Gold nanostars for superficial diseases: A promising tool for localized hyperthermia? Nanomedicine 2013, 9, 1-3. [CrossRef] [PubMed]

5. Guerrero-Martínez, A.; Barbosa, S.; Pastoriza-Santos, I.; Liz-Marzán, M.L. Nanostars shine bright for you: Colloidal synthesis, properties and applications of branched metallic nanoparticles. Curr. Opin. Colloid Interface Sci. 2011, 16, 118-127. [CrossRef]

6. Hao, F.; Nehl, C.L.; Hafner, J.H.; Nordlander, P. Plasmon resonances of a gold nanostar. Nano Lett. 2007, 7, 729-732. [CrossRef]

7. Barbosa, S.; Agrawal, A.; Rodriguez-Lorenzo, L.; Pastoriza-Santos, I.; Alvarez-Puebla, R.A.; Kornowski, A.; Weller, H.; Liz-Marzán, L.M. Tuning size and sensing properties in colloidal gold nanostars. Langmuir 2010, 26, 14943-14950. [CrossRef]

8. Weissleder, R. A clearer vision for in vivo imaging. Nat. Biotechnol. 2001, 19, 316-317. [CrossRef]

9. Smith, A.; Mancini, M.; Nie, S. Second window for in vivo imaging. Nat. Nanotechnol. 2009, 4, 710-711. [CrossRef]

10. Espinosa, A.; Silva, A.K.A.; Sánchez-Iglesias, A.; Grzelczak, M.; Péchoux, C.; Desboeufs, K.; Liz-Marzán, L.M.; Wilhelm, C. Cancer cell internalization of gold nanostars impacts their photothermal efficiency in vitro and in vivo: Toward a plasmonic thermal fingerprint in tumoral environment. Adv. Healthcare Mater. 2016, 5, 1040-1048. [CrossRef]

11. Wang, S.; Huang, P.; Nie, L.; Xing, R.; Liu, D.; Wang, Z.; Lin, J.; Chen, S.; Niu, G.; Lu, G.; et al. Single continuous wave laser induced photodynamic/plasmonic photothermal therapy using photosensitizer-functionalized gold nanostars. Adv. Mater. 2013, 25, 3055-3061. [CrossRef] [PubMed]

12. Yuan, H.; Fales, A.M.; Vo-Dinh, T. TAT peptide-functionalized gold nanostars: Enhanced intracellular delivery and efficient NIR photothermal therapy using ultralow irradiance. J. Am. Chem. Soc. 2012, 134, 11358-11361. [CrossRef] [PubMed]

13. González-Rubio, G.; Guerrero-Martínez, A.; Liz-Marzán, L.M. Reshaping, fragmentation and assembly of gold nanoparticles assisted by pulse lasers. Acc. Chem. Res. 2016, 49, 678-686. [CrossRef] [PubMed]

14. Pérez-Hernández, M.; Del Pino, P.; Mitchell, S.G.; Moros, M.; Stepien, G.; Pelaz, B.; Parak, W.J.; Gálvez, E.M.; Pardo, J.; Martínez de la Fuente, J. Dissecting the molecular mechanism of apoptosis during photothermal therapy using gold nanoprisms. ACS Nano 2015, 9, 52-61. [CrossRef] [PubMed]

15. Chen, J.; Wang, D.; Xi, J.; Au, L.; Siekkinen, A.; Warsen, A.; Li, Z.Y.; Zhang, H.; Xia, Y.; Li, X. Immuno gold nanocages with tailored optical properties for targeted photothermal destruction of cancer cells. Nano Lett. 2007, 5, 1318-1322. [CrossRef] [PubMed]

16. Huang, X.; Kang, B.; Qian, W.; Mackey, M.A.; Chen, P.C.; Oyelere, A.K.; El-Sayed, I.H.; El-Sayed, M.A. Comparative study of photothermolysis of cancer cells with nuclear-targeted or cytoplasm-targeted gold nanospheres: Continuous wave or pulsed lasers. J. Biomed. Opt. 2010, 15, 058002. [CrossRef]

17. ANSI. American National Standard for Safe Use of Lasers; Laser Institute of America: Orlando, FL, USA, 2000.

18. Ahijado-Guzmán, R.; González-Rubio, G.; Izquierdo, J.G.; Banares, L.; López-Montero, I.; Calzado-Martín, A.; Calleja, M.; Tardajos, G.; Guerrero-Martínez, A. Intracellular pH-induced tip-to-tip assembly of gold nanorods for enhanced plasmonic photothermal therapy. ACS Omega 2016, 1, 388-395.

19. Albanese, A.; Chan, W.C.W. Effect of gold nanoparticle aggregation on cell uptake and toxicity. ACS Nano 2011, 5, 5478-5489. [CrossRef]

20. Nativo, P.; Priot, I.A.; Brust, M. Uptake and intracellular fate of surface modified gold nanoparticles. ACS Nano 2008, 2, 1639-1644. [CrossRef]

21. Chitharani, B.D.; Ghazani, A.A.; Chan, W.C.W. Determining the size and shape dependence of gold nanoparticle uptake into mammalian cells. Nano Lett. 2006, 6, 662-668. [CrossRef] 
22. Iversen, T.-G.; Skotland, T.; Sandvig, K. Endocytosis and intracellular transport of nanoparticles: Present knowledge and need for future studies. Nano Today 2011, 6, 176-185.

23. Zhang, W.; Ji, Y.; Wu, X.; Xu, H. Trafficking of gold nanorods in breast cancer cells: Uptake, lysosome maturation and elimination. ACS Appl. Mater. Interfaces 2013, 5, 9856-9865. [CrossRef] [PubMed]

24. Kaliki, S.; Shields, C.L. Uveal melanoma: Relatively rare but deadly cancer. Eye (Lond.) 2017, 31, $241-257$. [CrossRef] [PubMed]

25. Yonekawa, Y.; Kim, I.K. Epidemiology and management of uveal melanoma. Hematol. Oncol. Clin. N. Am. 2012, 26, 1169-1184. [CrossRef] [PubMed]

26. Stein, J.D.; Childers, D.M.; Nan, B.; Mian, S.I. Gauging interest of the general public in laser-assisted in situ keratomileusis eye surgery. Cornea 2013, 32, 1015-1018. [CrossRef] [PubMed]

27. Kuryan, J.; Cheema, A.; Chuck, R.S. Laser-assisted subepithelial keratectomy (LASEK) versus laser-assisted in-situ keratomileusis (LASIK) for correcting myopia. Cochrane Database Syst. Rev. 2017, 2, CD011080. [CrossRef]

28. Gomel, N.; Negari, S.; Frucht-Pery, J.; Wajnsztajn, D.; Strassman, D.; Solomon, A. Predictive factors for efficacy and safety in refractive surgery for myopia. PLoS ONE 2018, 13, e0208608. [CrossRef]

29. Jimenez de Aberasturi, D.; Serrano-Montes, A.B.; Langer, J.; Henriksen-Lacey, M.; Parak, W.J.; Liz-Marzán, L.M. Surface enhanced Raman scattering encoded gold nanostars for multiplexed cell discrimination. Chem. Mater. 2016, 28, 6779-6790. [CrossRef]

30. Coelho, J.P.; González-Rubio, G.; Delices, A.; Osío Barcina, J.; Salgado, C.; Ávila, D.; Peña-Rodríguez, O.; Tardajos, G.; Guerrero-Martínez, A. Polyrotaxane-mediated self-assembly of gold nanospheres into fully reversible supercrystals. Angew. Chem. Int. Ed. 2014, 53, 12751-12755. [CrossRef]

31. Serrano-Montes, A.B.; Jimenez de Aberasturi, D.; Langer, J.; Giner-Casares, J.J.; Scarabelli, L.; Herrero, A.; Liz-Marzán, L.M. A general method for solvent exchange of plasmonic nanoparticles and self-assembly into SERS-active monolayers. Langmuir 2015, 31, 9205-9213. [CrossRef]

32. Pelaz, B.; del Pino, P.; Maffre, P.; Hartmann, R.; Gallego, M.; Rivera-Fernández, S.; Martínez de la Fuente, J.; Nienhaus, G.U.; Parak, W.J. Surface functionalization of nanoparticles with polyethylene glycol: Effects on protein adsorption and cellular uptake. ACS Nano 2015, 9, 6996-7008. [CrossRef] [PubMed]

33. Pardo, M.; Piñeiro, A.; de la Fuente, M.; García, A.; Prabhakar, S.; Zitzmann, N.; Dwek, R.A.; Sánchez-Salorio, M.; Domínguez, F.; Capeans, C. Abnormal cell cycle regulation in primary human uveal melanoma cultures. J. Cell. Biochem. 2004, 93, 708-720. [CrossRef] [PubMed] 